\title{
Some Sources of Misunderstandings in Intercultural Business Communication
}

\author{
T. Lázár \\ University of Debrecen Faculty of Economics and Business, lazar.timea@econ.unideb.hu
}

Abstract. It is always a big challenge for all types of companies anywhere in the world to survive in the globalised and accelerated world. Their primary objective is to stay competitive, keep or even enlarge their market share while keeping their costs at a minimum level. These corporations often cross borders and operate on a multinational level. In order to do that successfully they need flexible workforce: people who have a high level of intercultural competencies and can help their corporations to achieve their aim of profit maximising. It is widely accepted that culture and languages are among the most significant impacts on intercultural communication. In this paper first I am going to interpret intercultural communication and the role of culture and then look at different intercultural skills and the role of languages in intercultural communication. Some areas that might cause problems in intercultural business communication will also be described.

\section{Introduction}

In order for any company to survive in our globalised and accelerated world, a multitude of challenges must be faced on a daily basis. A company's primary objective is to stay competitive; to retain or even enlarge market share while keeping costs at a minimum. Indeed, a company can be competitive only by reinventing itself, through the use of new forms of business, by forming alliances to cut costs and by enlarging the customer base. In the business world, change happens so fast that companies must be flexible and able to adapt at all times. In some cases, business organisations are forced to cross borders and operate on a multinational level. In order to succeed, they need flexible workforces, i.e. people who have intercultural competencies and capable of assisting them to achieve their business objectives [36]. Business communication in such organisations must accommodate workers coming from different cultural backgrounds, possessing intercultural communication skills which allow them to act successfully on the international level. Such employees either work in multinational teams, take part in multinational business meetings and negotiations or go on assignments to other countries. Proper knowledge of the cultures and foreign languages such employees will meet and use will shape the ways in which they either master or fail in their intercultural communication situations [38]. In this paper, I discuss intercultural communication and the role of culture, examining different intercultural skills and the role of languages in intercultural communication. I also describe specific areas that cause problems in intercultural business communication. 


\section{Intercultural Communication}

It was Edward T. Hall who first used this term in 1959 for communication between persons of different cultures. Today it is universally accepted that different skills are needed to be able to communicate successfully with someone from another culture [12].

Seelye (1993) enlisted six basic skills forming intercultural competences: cultivating curiosity about another culture and empathy toward its members, recognizing that role expectations and other social variables such as age, sex, social class, religion, ethnicity, and place of residence affect the way people speak and behave, realizing that effective communication requires discovering the culturally conditioned images that are evoked in the minds of people when they think, act, and react to the world around them; recognizing that situational variables and convention shape our behaviour in important ways, understanding that people generally act the way they do because they are using options their society allows for satisfying basic physical and psychological needs, and that cultural patterns are interrelated and tend to support need satisfaction mutually, developing the ability to evaluate the strength of a generalization about the target culture, and to locate and organize information about the target culture from the library, the mass media, people, and personal observation.

Several authors mentioned that intercultural competences are needed in the era of globalisation and they tried to define what they were. Chen and Starosta (1997) used the term intercultural sensitivity and they wrote that with the appearance of global society people need to adapt to the unfamiliar and there is a strong demand for greater understanding, sensitivity and competency among people from differing cultural backgrounds. To behave effectively and appropriately in intercultural interactions people need intercultural competence: self-esteem, self-monitoring, open-mindedness, empathy, interaction involvement and suspending judgement. Hunter et al (2006) used the phrase global competence, which is the capability to understand one's own culture and identify cultural differences to other cultures.

Within the wide spectrum of intercultural competences the intercultural communication competence plays a significant role. Waldeck et al (2012) defined six communication competencies important within the contemporary business environment. Spitzberg (2000) created a "Model of Intercultural Communication Competence" and he enlisted more empirically derived factors. Makela et al (2007) did research on the interpersonal similarity in multinational corporations. The different intercultural competencies are the following:

- $\quad$ ability to adjust to different cultures [32]

- social adjustment [32]

- awareness of implications of cultural differences [32]

- national-cultural similarity [23]

- cultural empathy [32]

- cultural interaction [32] 
- communication competence [32]

- communication apprehension [32]

- communication of enthusiasm, creativity, and entrepreneurial spirit [38]

- relationship and interpersonal communication skills [38]

- mediated communication [38]

- intergroup communication [38]

- nonverbal communication [38]

- interpersonal flexibility [32]

- interpersonal harmony [32]

- interpersonal interest [32]

- speaking and listening [38]

- a shared language [23]

- $\quad$ ability to deal with psychological stress [32]

- cautiousness [32]

Steele and Plenty (2015) defined intercultural communication competence as "one's knowledge of appropriate communication practices as well as effectiveness at adapting to the surroundings in a communication situation." [33]

\section{The Importance of Cultural Background in Intercultural Communication}

In every form of communication the key to understanding is the meaningful context. Communicators make statements assuming that the other party has the same context of the statement. But in the case of communicators from different cultural backgrounds this is not always necessarily the case. If one understands the language and the words it is not sure that they understand the message, too. Understanding the culture can help communicators understand the context and the message. It might sound easy to achieve but in fact it is not. First of all it is not easy to define culture as such. Originally the world culture was used by ancient Roman orator Cicero and he used it for the cultivation of the soul. Culture can be defined broadly and it can affect many aspects of human life. In 1952 Kroeber and Kluckhohn collected more than 150 definitions of the term. "The essence of culture is not what is visible on the surface. It is the shared ways groups of people understand and interpret the world." [35]

Culture has an impact on business in different forms: there are international managers who operate on several different premises [18]. Trompenaars and Hampden-Turner (1993) wrote that there is a presumption that internalisation will lead to a common culture all over the world, and tastes and markets, thus culture are becoming more and more similar.

"Whereas communication is a process, culture is the structure through which the communication is formulated and interpreted. Culture deals with the way people live." [24] In intercultural communication different cultures interact and might influence each other, so if you 
are not familiar with the given culture at least partly, it can hinder or deteriorate successful communication.

If people have to function in another culture it is natural that they experience difficulties. Brislin and Cushner (1996) wrote about areas of difficulties such as: dealing with anxiety whose origins are typically vague, learning new culturally appropriate behaviours, having to make decisions based on less information than one is accustomed to, recognising new clues to the role and how one is expected to interface with that role.

When one communicates with people from another culture there might be communication barriers which are obstacles to effective communication. Chaney and Martin (2014) enlisted the following handicaps: (p. 12) physical (time, environment, comfort and needs, and physical medium), cultural (ethnic, religious, and social differences), perceptual (viewing what is said from your own mindset), motivational (the listener's mental inertia), experiential (lack of similar life happenings), emotional (personal feelings of the listener), linguistic (different languages spoken by the speaker and listener or use of a vocabulary beyond the comprehension of the listener), nonverbal (non-word messages) and competition (the listener's ability to do other things rather than hear the communication).

Cultural differences obviously influence the different styles of management. Hanges et al (2016) conducted research on cross-cultural leadership and they found that culture moderates the outcomes resulting from different styles of leadership. They found that different leadership styles can be more effective if the followers are culturally homogenous at least to a certain extent.

Artiz and Walker (2010) studied how member participation in meetings changes when teams are formed on multicultural basis using discourse analysis and observational methods. They found that there were significant differences in the discourse patterns of U.S.-born English speakers and their Asian-speaking counterparts when speaking English and working in mixed groups. Their research showed that group composition affected communication patterns.

Shieh et al (2009) found that failures suffered by multinational enterprises generally result from neglecting cultural differences and managers must be cross-culturally trained to face the challenges of global competition. Tutar et al (2014) found that multinational company managers are aware of cultural differences and they have the skills to turn cultural differences into advantages as today multinational companies have workforce from different cultures, and managers need to take these differences into consideration in their activities.

In the case of international companies intercultural communication differences can cause serious problems, Laurig (2011) established that differences in styles of communication could slow down the process of decision making and weaken social ties or they could make working processes more difficult. Levitt (2014) tried to explore cultural factors affecting international team dynamics and effectiveness and he found that cultural differences created more frustrations and barriers to effective teamwork than benefits. 
Global economic crises have multicultural effects. Oliveira's findings (2013) confirmed that even in crisis communication cultural diversity had a significant effect and understanding cultural differences was an important requirement in our society.

\section{The Role of Language in Intercultural Communication}

Very often intercultural communication means communication in a foreign language with someone for whom our mother tongue is a foreign language. One can speak a foreign language fluently but is it enough to understand foreign cultures? According to the Sapir-Whorf hypothesis, how a nation views the world depends on the language system a particular nation has [24]. Also, there is a strong relation between language and the culture of the language community [17]. If we intend to develop intercultural communication skills, we should learn both the language and its cultural context at the same time. Those students who learn the language in its original setting have an advantage over those who learn it in their own cultural setting. Therefore students learning in a foreign country more readily succeed at intercultural communication, because they have the chance to understand and know the other culture, besides acquiring the target foreign language.

One feature of today's labour market is the increasing need for new employment competencies. There are universally required skills, which are often mentioned as transversal or non-domain specific competencies, including communication skills with the sub-categories of foreign language proficiency and intercultural competencies. Higher education institutions are expected to react to the most recent tendencies of the job market both in terms of content and method and involve the new demands in their study programs [10].

As intercultural communication competencies are pivotal in business world many researchers tried to find what influence them and how to improve them. Williams (2005) conducted a research in which he compared students who had studied abroad for one semester with students who had stayed on campus and his results confirmed that students who study abroad exhibit a greater change in intercultural communication skills after their semester abroad than students who stay on campus. He found that exposure to various cultures is the best predictor of intercultural communication skills.

It is generally accepted that English is considered the language of international business. But there are many varieties of the English language, such as British English, American English, Australian English, African English etc. that even for native speakers of English unfamiliar accents and phrases may present barriers to effective communication. Furthermore, there are communicators who speak English as a second language communicating in English with native speakers of English. And there are communicators communicating in English when for all parties English is a second language. In all of these cases the difficulties that communicating in English represents are different. Henderson (2005) studied how language diversity in a team affects the ability of individuals to interpret each other's specific communication practices and general language behaviour and found that both native and non-native speakers of English tend to view 
language and communication from a national, monocultural perspective. He found that when all the participants used English as the working language they had that false impression that the words and expressions have the same context, interpretation and connotations for all speakers whether they come from the US, India, France, and Denmark. But this was not the case as the same practices and routines were not valid for everybody.

Charles (2007) did research on language and communication in multinational corporations based in non-English speaking countries and found that language can unite people and businesses, but it may divide them, too.

New demands in the economy and society have encouraged changes in the content of foreign language education as well. As foreign language competencies have become vital in the communication of organisations, today's language teaching focuses on Office English or Business English when teaching students or adults, and intercultural skills form an essential part of Business or Office English [10].

To overcome difficulties when English is used as a common working language within the organisation communicators use simple patterns. According to Chaney and Martin (2014) for written communication patterns businesses use international English that is they use the 30004000 most common English words and they use short, simple sentences.

For successful intercultural communication the communicators should share a common language or else they would need a third party involved i. e. an interpreter. But choosing the suitable person to interpret during a multicultural business meeting is a difficult task. It is useful if the interpreter is bilingual and bicultural, but at least perfectly familiar with the communicators' business culture. The success or the failure of a negotiation depends on the interpreter. The parties in the negotiation provide all the help the interpreters need for the successful outcome, that is: try to help them with the technical terms in advance, provide visual aids where necessary, be careful with the use of words during the talks and try to get feedback continuously.

When we have to translate in intercultural communication it can also cause some problems. The most obvious one is that the original meaning may be lost simply because the exact words may not exist in the other language. In the case of translations the use of informal language can be difficult, too.

An additional aspect that can cause misunderstandings is the use of informal language: using slang, colloquialism, acronyms, euphemisms, idioms and jargon.

Tenzer and Pudelko (2015) found that language barriers can cause negative emotions among members in multinational teams. This is an issue that global leaders must pay attention to.

Seelye (1993) wrote that if we have to function within another language, it inevitably changes our way of life as well, so we can say that there is an interaction between linguistic and social change. 
In conclusion, "Language is, of course, a major vehicle for the transmission of culture. Learning the cultural roots of a language is essential for meaningful fluency." [29]

\section{Some other areas of misunderstandings in intercultural communication caused by cultural differences}

In successful intercultural communication participants need to speak a common language properly, they need to be aware of the cultural differences and should take them into consideration, but in some situations misunderstandings can arise even if the participants fulfil the above-mentioned requirements. According to Larkey (1996) in culturally diverse workgroups misunderstanding may come from misinterpretations of intent, organisational practices, or interpersonal reactions, as well as simple miscommunication of ideas or values.

There are different areas of language use which might cause problems in intercultural communication. One of these areas is the language of numbers. In written communication there are differences in using decimal points in different parts of the world. In some countries they use the decimal point to separate thousands (in most European countries) while in the United States they use the comma. Another example is the use of billion and milliard for numbers with nine zeros. In some countries they use the phrase billion (US, Britain etc.) and in other countries they use milliard for the same number (Russia, Italy, Germany etc.) [7].

Although the metric system was designed to be universal all over the world, the conversion of scientific units into their SI equivalents might be problematic. There are different systems of units in use in various areas of science. For example the British system of units, known as imperial units and the similar US Customary Units, which are legal in the USA and Canada [6].

There are other aspects which are in close relation with cultural differences which can be the inward, non-verbal intercultural communication. They are gestures, facial expressions, interpersonal distance, eye contact, touch and silence. Some important areas of causing misunderstanding are listed below, but they are just examples, of course there can be a lot more [31].

The prevention or handling of possible misunderstandings can be led by philosophy and useful methodology in the field of corporate social responsibility (CSR). Existing mentor programs, for example can protect intergeneration conflicts [3].

One of the important areas to avoid future misunderstandings is the attitude toward time because it can vary from culture to culture. For example people in Latin America, Southern Europe, and the Middle East have different attitudes toward punctuality and interruptions than people in the United States, England, Germany or Switzerland [37].

Also, the layout of the office and the arrangement of furniture play an important role in different cultures. This can convey power and show status [28]. 
In an intercultural business context even using colours can cause problems because there are some cultural differences associated with colours. Just to mention one example: black is the colour of mourning in many European countries and in the United States, too. However, in Japan and some other countries it is white, and on the African continent red has similar connotations [2].

Another important area of nonverbal communication is clothing. In some cultures dressing conservatively or casually reflects different messages and can be associated with social status or wealth [24].

When doing business internationally you must apply the correct interpersonal space during conversations. There can be differences in the appropriate space in different cultures. For example people in the United States need more space than people in Latin America, but the Japanese need even more space [25].

Body language is an important part of the communication process in any culture. This may take different forms, for example facial expressions, gestures and posture. In many cases gestures depend on the culture and the context, and to avoid misinterpretations use them with care in international business settings [22]. Another difference can be found in using touches and body contacts in intercultural business communications. Shaking hands is accepted in many cultures, hugging on the other hand may seem inappropriate in some cultures. In countries like Italy, Greece, Spain touching is tolerated whereas in Hong Kong for example, any type of physical contact is best avoided [7].

In some business cultures people favour direct eye contact, for example in the US, Great Britain, Eastern Europe, while in other cultures eye contact is avoided, and for example in the Middle East there is a prolonged eye contact which can be uncomfortable for those who are not accustomed to it. There can be cultural variations concerning the eye contact with women in different cultures. If you are not familiar with these customs you can misinterpret the eye contact [4].

In many countries in business meetings there is a given amount of "small talk" before getting down to business. But this might be a minefield for intercultural communicators as there are differences concerning the topics of this "small talk": it is appropriate to talk about some topics in some countries but they are considered inappropriate in other countries. Problematic topics could be politics, religion and family situations [26].

The role of silence as a form of nonverbal communication is different in different cultures. Some might interpret it as a sign of agreement, while others as a lack of interest [15].

These examples illustrate that communicators should take many aspects of intercultural business communication into consideration, which requires intercultural competencies, preparation and experience. These skills can be improved and nowadays multinational companies realise how important they are and they are willing to invest in improving them. 


\section{Conclusion}

Intercultural communication is determined by sociocultural, and psychological considerations The success or failure of intercultural communication can depend on different factors but we can agree that culture has a very important role in it. There is a large variety of skills that communicators need to develop in intercultural communication and the more they have the better communicators they can be. The lack of a common language can act as a barrier to successful intercultural communication but this is not the only factor. There are a lot of other areas which might cause problems in intercultural communication so it is advisable to be well prepared before you communicate with people from other cultures. . Moreover, there is a growing interest in intercultural communication in international business life. Investment in exploring and developing the intercultural communication potential of employees is no longer a challenge, but should be a part of duties in everyday business operation, and also in strategical thinking.

\section{References}

[1] J. Artiz, R. C. Walker (2010), Cognitive organisation and identity maintenance in multicultural teams: A discourse analysis of decision-making meetings, Journal of Business Communication

[2] M. M. Aslam (2006), Are you selling the right colour? A cross-cultural review of colour as a marketing cue, Journal of Marketing Communications, 12. 1: 15-30.

[3] A. Bene, P. Salamon (2016), CSR Potential, The Publications of the MultiScience - XXX. microCAD International Multidisciplinary Scientific Conference. University of Miskolc

[4] C. Blais, R. E. Jack, C. Scheepers, D. Fiset, R. Caldara (2008), Culture shapes how we look at faces, PloS one, 3. 8: e3022.

[5] R. W. Brislin, K. Cushner (1996), Intercultural Interactions: A Practical Guide, Sage Publications, Thousand Oaks

[6] F. Cardarelli (2012), Scientific unit conversion: a practical guide to metrication Springer Science \& Business Media

[7] L. Chaney, J. Martin, (2014), Intercultural Business Communication, Pearson Education Limited, Harlow

[8] M. Charles (2007), Language matters in global communication article based on ORA lecture, October 2006, Journal of Business Communication, 44. 3: 260-282.

[9] G. M. Chen, W. J. Starosta (1997), A review of the concept of intercultural sensitivity, Human Communication, 1: 1-16.

[10] M. Czellér, Z. Hajdu (2014), Incorporating Blended Learning in Teaching English for Specific Purposes, Economica, 7. 4: 155-163. 
[11] Z. Hajdu, M. Czellér (2016), Adapting foreign language education to the expectations of the labour market, In: Nataša Gajšt, Alenka Plos, Polona Vičič (eds.) The ninth international language conference on the importance of learning professional foreign languages for communication between cultures. 2016. 09. 22-2016. 09. 23. Maribor, Slovenia, 63-67.

[12] E. T. Hall (1959), The Silent Language, Doubleday \& Company, Inc., Garden City, New York, 242.

[13] P. J. Hanges, J. R. Aiken, J. Park, J. Su (2016), Cross-cultural leadership: leading around the world, Current Opinion in Psychology, 8: 64-69.

[14] J. K. Henderson (2005), Language diversity in international management teams, International Studies of Management \& Organization, 35. 1: 66-82.

[15] X. Huang, E. Van de Vliert, G. Van der Vegt (2005), Breaking the silence culture: Stimulation of participation and employee opinion withholding cross-nationally, Management and Organization Review, 1. 3: 459-482.

[16] B. Hunter, G. P. White, G. C. Godbey (2006), What does it mean to be globally competent? Journal of Studies in International Education, 10. 3: 267-285.

[17] W. Jiang (2000), The relationship between culture and language, ELT journal, 54. 4: 328-334.

[18] A. L. Kroeber, C. Kluckhohn (1952), Culture: A critical review of concepts and definitions, Papers - Peabody Museum of Archaeology \& Ethnology, Harvard University

[19] L. K. Larkey (1996), Toward a theory of communicative interactions in culturally diverse workgroups, Academy of Management - Review, 21. 2: 463-491.

[20] J. Lauring (2011), Intercultural organizational communication: The social organizing of interaction in international encounters, Journal of Business Communication, 0021943611406500

[21] S. R. Levitt (2014), Cultural Factors Affecting International Teamwork Dynamics, International Journal Of Knowledge, Culture \& Change In Organizations: Annual Review, 13.

[22] R. D. Lewis, M. Gates (2005), Leading Across Cultures, Nicholas Brealey

[23] K. Makela, H. K. Kalla, R. Piekkari (2007), Interpersonal similarity as a driver of knowledge sharing within multinational corporations, International Business Review, 16. 1: 1-22.

[24] J. S. Martin, L. H. Chaney (2012), Global Business Etiquette: A Guide to International Communication and Customs: A Guide to International Communication and Customs, ABCCLIO

[25] D. Matsumoto (2006), Culture and nonverbal behavior, Handbook of nonverbal communication, 219-235.

[26] C. Meierkord (2013), Interpreting successful lingua-franca interaction. An analysis of nonnative-/non-native small talk conversation in English, Linguistik online, 5. 1. 
[27] M. de F. Oliveira (2013), Multicultural environments and their challenges to crisis communication, The Journal of Business Communication, 50. 3: 253-277.

[28] K. Sailer, I. McCulloh (2012), Social networks and spatial configuration - How office layouts drive social interaction, Social networks, 34. 1: 47-58.

[29] H. N. Seelye (1993), Teaching culture - Strategies for Intercultural Communication, National Textbook Company, Lincolnwood

[30] Ch-J. Shieh, I. Wang, F-J. Wang (2009), The relationships among cross-cultural management, learning organization, and organizational performance in multinationals, Social Behavior and Personality: an international journal, 37. 1: 15-30.

[31] E. Sotoudehnama, F. Solgi (2013), Nonverbal Messages and Intercultural Communication, Iranian Journal of Applied Language Studies, 5. 1: 170-189.

[32] B. H. Spitzberg (2000), A model of intercultural communication competence, Intercultural communication: A reader, 9: 375-387.

[33] G. A. Steele, D. Plenty (2015), Supervisor-subordinate communication competence and job and communication satisfaction, International Journal of Business Communication, 52. 3 : 294-318.

[34] H. Tenzer, M. Pudelko (2015), Leading across language barriers: Managing languageinduced emotions in multinational teams, The Leadership Quarterly 26. 4: 606-625.

[35] F. Trompenaars, C. Hampden-Turner (1993), Riding the waves of culture: Understanding diversity in global business, Nicholas Brealey Publishing

[36] H. Tutar, M. Altinoz, D. Cakiroglu (2014), A Study on Cultural Difference Management Strategies at Multinational Organizations, Procedia-Social and Behavioral Sciences, 150: 345-353.

[37] J-C. Usunier (2003), Cultural aspects of international business negotiations, International business negotiations, 2: 97-135.

[38] J. Waldeck, C. Durante, B. Helmuth, B. Marcia (2012), Communication in a changing world: Contemporary perspectives on business communication competence, Journal of Education for Business, 87. 4: 230-240.

[39] T. R. Williams (2005), Exploring the impact of study abroad on students' intercultural communication skills: Adaptability and sensitivity, Journal of studies in international education, 9. 4: 356-371. 